\title{
A RELAÇÃo ENTRE O PÚBLICO E O PRIVAdO NO IMPEACHMENT DE DILMA ROUSSEFF
}

\author{
The relationship between the public and private sphere in Dilma Rousseff's impeachment
}

\author{
Frederico Rios C. dos Santos ${ }^{1}$ \\ Universidade de São Paulo/ Capes
}

\begin{abstract}
RESUMO
O trabalho tem o objetivo de verificar a presença de valores e aspectos dóxicos no discurso político afeitos ao patrimonialismo. Servindo-se do corpus representado pela votação do impeachment de Dilma Rousseff na Câmara dos Deputados, pergunta-se se a menção a cena patrimonialista no discurso é acompanhada, por atração isotópica, de outros elementos ligados ao discurso conservador ou progressista, segundo os parâmetros de Bobbio (2011) e Charaudeau (2016). A pesquisa apontou para o fato de que a maioria dos votantes, ao apresentar um discurso patrimonialista, empregou estratégias retóricas próprias da direita política conservadora, votando massivamente pela saída da ex-presidente.
\end{abstract}

Palavras-chave: Discurso. Retórica. Argumentação. Patrimonialismo. Impeachment. Dilma Rousseff.

\section{ABSTRACT}

The work aims to verify the presence of values and doxic aspects in political discourse related to patrimonialism. Using the corpus represented by the Dilma Rousseff's impeachment vote in the Chamber of Deputies, one wonders whether the mention of a patrimonialist scene in the speech is accompanied, by isotopic attraction, of other elements linked to the conservative or progressive discourse, according to the Bobbio (2011) and Charaudeau's (2016) parameters. The research pointed to the fact that the majority of voters, when presenting a patrimonialist discourse, used rhetorical strategies typical of the conservative political right, massively voting for the ex-president's departure.

Keywords: Discourse. Rhetoric. Argumentation. Patrimonialism. Impeachment. Dilma Rousseff.

\section{RESUMEN}

El trabajo tiene como objetivo verificar la presencia de valores y aspectos dóxicos en el discurso político relacionado con el patrimonialismo. Utilizando el corpus representado por el voto de destitución de Dilma Rousseff en la Cámara de Diputados, preguntase si la mención de la escena patrimonialista en el discurso está acompañada, por atracción isotópica, de otros elementos vinculados al discurso conservador o progresista, de acuerdo con los parámetros de Bobbio (2011) y Charaudeau (2016). La investigación señaló que la mayoría de los votantes, cuando presentaron un discurso patrimonialista, utilizaron estrategias retóricas típicas de la derecha política conservadora, votando masivamente por la partida de la expresidenta. Palabras clave: Discurso. Retórica. Argumentación. Patrimonialismo. Impeachment. Dilma Rousseff.

Recebido em: janeiro 2020

Aceito em: junho 2020

DOI: $10.26512 /$ les.v21i1.29344

\footnotetext{
${ }^{1}$ Doutor em Linguística do Texto e do Discurso (UFMG). Já realizou estágios de pesquisa na Sorbonne e na Sciences Po Paris. É membro da Associação Latino-Americana de Retórica, da Associação Latino-Americana de Estudos do Discurso, entre outras. Atua como pesquisador no Grupo Retórica e Argumentação, da UFMG, e no Núcleo de Estudos em Análise Crítica do Discurso, da USP. É autor do livro "Cinema, Discurso e Relações Internacionais: perspectivas teóricas e princípios de análise". E-mail: fredericodesantos@gmail.com
} 


\section{INTRODUÇÃO}

A palavra doxa tem origem etimológica no grego antigo, sugerindo tratar-se de opiniões comuns que circulam na sociedade, representações majoritárias que se se espraiam, conformando os saberes coletivos e os pré-construídos culturais.

O artigo tem como objetivo verificar o emprego dessas opiniões comuns e de valores ligados ao patrimonialismo, bem como identificar a qual matriz ideológica do discurso político o patrimonialismo pode estar mais associado, se ao discurso conservador ou ao progressista, no impeachment de Dilma Rousseff. Para isso, lança-se mão do corpus representado pelos discursos da votação de admissibilidade do rito na Câmara dos Deputados.

Assim, em um primeiro tópico, é dado destaque à problematização do conceito de "doxa", especificamente no que diz respeito ao discurso conservador e ao progressista, com o auxílio de cientistas da linguagem como Amossy (2018), Grácio (2010), Plantin (2018) e Charaudeau (2016), assim como do filósofo político Bobbio (2011).

$\mathrm{Na}$ seção seguinte, faz-se uma análise quantitativa e outra qualitativa dos 511 pronunciamentos do impeachment na Câmara dos Deputados. O objetivo da análise quantitativa é o de obter uma visão panorâmica do corpus para procurar descrevê-lo com propriedade e servir como balizamento para as análises qualitativas (de cunho crítico, o cerne do trabalho) que se seguem.

Para a análise quantitativa, procurou-se, em um primeiro momento, categorizar os discursos de acordo, por exemplo, com a decisão (se "sim" ou "não" ao impeachment); com a referência ou não à palavra "Deus" ou à própria religião, bem como a qualquer outro traço que denote a presença de um discurso religioso; com a citação ou não da própria família, da própria região eleitoral, entre outras constantes consideradas por Charaudeau (2016) e Bobbio (2011) como próprias do discurso político conservador. Isso para verificar se o uso de uma cena patrimonialista no discurso é acompanhado, por atração isotópica, de outros aspectos comuns ao conservadorismo, como se supõe, segundo os autores em questão.

Em seguida, são selecionados discursos que sejam representativos de cada uma dessas constantes, para, à luz de referenciais teórico-metodológicos propostos pelos autores mencionados, entre outros (discriminados quando das análises) proceder-se à crítica dos discursos. 


\section{OS ASPECTOS DOXICOS ${ }^{2}$ DAS MATRIZES IDEOLOGICAS DO DISCURSO POLITICO}

A conceituação do termo "doxa" é controversa. De acordo com o Dicionário de Argumentação de Plantin (2018), a palavra tem a origem etimológica no grego antigo, significando reputação, opinião ou o que é dito das pessoas ou coisas. São as representações majoritárias que se difundem na sociedade.

A palavra pode assumir uma valência negativa, remetendo à ideia de clichê, estereótipo, lugar comum, ideologia ou dogma (Amossy, apud Plantin, 2018). Essa é a visão de Rui Grácio:

[...] a inserção numa cultura leva-nos a pensar «culturalmente» e submete-nos às crenças e às descrenças estabelecidas, às confianças e às desconfianças que são a regra e, nesse sentido, tornam o discurso que se apresenta como próprio numa fala ventríloqua que se limita, ou pouco mais faz, do que articular tipos, estereótipos e clichés (GRÁCIO, 2010, p. 36).

No interior de uma análise do discurso que não se quer normativa, mas que busca compreender os modos de funcionamento do discurso na sociedade, a carga pejorativa de termos como "clichê" e "estereótipo" perde a sua razão de ser. Isso porque, partindo-se do pressuposto que é da constituição da linguagem a remissão a um regime de crenças, então não faria sentido o analista elaborar juízos de valor acerca dos aspectos dóxicos que encontra nos discursos. Nas palavras de Amossy,

[...] é preciso conceber o estereótipo como um elemento dóxico obrigatório sem o qual não somente nenhuma operação de categorização ou de generalização seria possível, mas também nenhuma construção de identidade e nenhuma relação com o outro poderia ser elaborada. Como todo elemento dóxico, o estereótipo tem um papel importante na argumentação (AMOSSY, 2018, p. 131).

É por isso que Charaudeau (2007) busca se desvincular do ranço negativo das palavras estereótipos, clichês, lugares comuns etc., para adotar um termo mais neutro denominado “imaginários sociodiscursivos". De acordo com o linguista francês:

É a presença dessa suspeita [negativa] que torna difícil a recuperação da noção de estereótipo para tomá-lo como conceito. Em primeiro lugar, porque essa noção é dependente do julgamento de um sujeito, e porque esse julgamento, sendo negativo, oculta a possibilidade de que tudo que é dito guarda consigo uma parte de verdade [...]. É preciso conceder ao estereótipo a possibilidade de dizer ao mesmo tempo o

\footnotetext{
2 Preferiu-se adotar aqui o termo genérico "aspecto dóxico" para se referir a manifestações dóxicas em geral, não necessariamente às que Amossy (2014) denomina de elementos dóxicos, como os clichês, os estereótipos e os lugares comuns, pois, como se verá, essa terminologia é problemática.
} 
falso e o verdadeiro. Todo dizer sobre o outro é, ao mesmo tempo, um dizer sobre si mesmo [...] (CHARAUDEAU, 2007, p. 1, tradução nossa $\left.{ }^{3}\right)$.

Nessa perspectiva, o que se denomina por estereótipo pode apresentar uma visão reducionista ou distorcida da realidade, mas, ao mesmo tempo, uma visão de mundo de um enunciador que é típica de uma dada sociedade. Trata-se de uma visão que é real, no sentido de que está aí, circulando, e que proporciona reações. De acordo com Amossy,

A análise da argumentação no discurso a concebe como enraizada em uma doxa que atravessa inconscientemente o sujeito falante, que a ignora porque está profundamente imerso nessa argumentação. Se a argumentação implica uma intencionalidade e uma programação, estas se revelam tributárias de um conjunto dóxico que condiciona o locutor, do qual ele está, muito frequentemente, longe de ter clara consciência. [...]. O locutor, que se engaja em uma troca para pôr em evidência o seu ponto de vista, está tomado por um espaço dóxico que determina a situação de discurso em que ele argumenta, modelando a sua palavra até o centro de sua intencionalidade e de seu planejamento (AMOSSY, 2018, p. 112-113).

Em contexto de guerra cultural, alguns aspectos dóxicos mobilizados são os concernentes aos embates entre uma esquerda progressista e uma direita conservadora. Para Bobbio (2011) e Charaudeau (2016), existiriam constantes universais que caracterizariam os valores dos dois polos da polêmica, a despeito de idiossincrasias apresentadas no espaço e no tempo.

Apesar de o conceito de doxa não corresponder necessariamente ao de valor, uma análise daquela precisa passa por este. Por exemplo, é difícil falar em opiniões comuns como "lugar de mulher é na cozinha", ou "mulher não é dona do próprio corpo, por isso toda forma de aborto deve ser criminalizada", sem passar pelo valor do patriarcado ou da família tradicional.

De acordo com Bobbio (2011), o valor mais compartilhado no polo da esquerda progressista da guerra cultural é o do igualitarismo. Assim, a doxa de que é preciso uma intervenção estatal para a promoção da igualdade entre os indivíduos é onipresente nesse cenário. Do outro lado da polêmica, da direita conservadora, o valor que se sobrepõe aos demais é o do mérito, seja ele econômico, de nascença, ou de pertencer a uma maioria, o que acaba por justificar algumas posições comuns que defendem a permanência de desigualdades.

Charaudeau (2016) possui uma visão semelhante. Para o autor, existiria um sistema de crenças que ele denomina de "matrizes ideológicas". A matriz ideológica de direita é própria da crença segundo a qual a natureza se impõe sobre os homens, daí porque a desigualdade pode ser

\footnotetext{
3 Original: C'est la présence de ce soupçon [négatif] qui rend difficile la récupération de la notion de stéréotype pour en faire un concept. D'abord parce que cela signale que cette notion est dépendante du jugement d'un sujet, et que ce jugement en étant négatif occulte la possibilité que ce qui est dit renferme malgré tout une part de vérité [...]. Il faut accorder au stéréotype la possibilité de dire quelque chose de faux et vrai, à la fois. Tout jugement sur l'autre est en même temps révélateur de soi $[\ldots]$.
} 
legitimada por ser consubstancial à natureza humana. $\mathrm{O}$ corolário desse regime de verdade é que determinadas relações de dominação seriam perfeitamente justificáveis.

Esse posicionamento, para Charaudeau (2016), possibilita a defesa de outros valores como o da família, na figura do patriarcado, uma ordem legitimamente hierárquica; o valor do trabalho, pensado como atividade vertical entre superiores (empresários) e inferiores (empregados); e o valor da nação, justificando a insurgência contra qualquer suspeito de invasão.

Esses valores da matriz ideológica de direita tenderiam, para Charaudeau (2016), ao conservadorismo, para que as estruturas hierárquicas na sociedade e na família se mantenham; ao segregacionismo, dividindo visões de mundo; ao autoritarismo, para que não haja ameaça ao status quo; e ao patriarcado, no intuito de se manter um sistema de instrução familiar que conserve o "mérito natural" dos sujeitos (Charaudeau, 2016).

Em contrapartida, a matriz ideológica de esquerda toma como princípio a possibilidade de o homem ser capaz de dominar a natureza, o que o estimula desconstruir desigualdades impostas pelo meio rumo a uma sociedade mais igualitária. Nesse regime de verdade, encontram guarita os discursos que busquem a supressão de privilégios e da discriminação, a solidariedade social e o laicismo. Daí porque a defesa de uma democracia plural, laica e inclusiva se faz uma constante nesse espectro ideológico (Charaudeau, 2016).

No tópico seguinte, serão analisados esses regimes de crenças da guerra cultural nos discursos do impeachment de Dilma Rousseff na Câmara dos Deputados, ressaltando os aspectos dóxicos e valores que se apresentaram de forma mais significativa, no que diz respeito especificamente ao discurso patrimonialista, associado, por atração isotópica, a outros discursos considerados como conservadores.

\section{Percursos do Patrimonialismo}

De acordo com Charaudeau (2016), a matriz ideológica de direita tende, em sua lógica segundo a qual as desigualdades são naturais, a defender o valor família, porque, em sua ótica, o indivíduo é determinado pelo grupo que, por sua vez, depende da filiação. Isso implica a opinião comum de que as relações hierárquicas e patriarcais devem ser conservadas:

A matriz ideológica de direita se caracteriza por uma visão do mundo na qual 'a natureza se impõe ao homem, o que significa que este é determinado, que, portanto, a desigualdade é consubstancial à natureza humana, e que, consequentemente, as relações que os homens estabelecem entre si são relações de poder, de dominação. Esse posicionamento engendra a defesa de certos valores [dentre os quais] o valor do grupo familiar, já que não é o indivíduo que fabrica o grupo, mas o grupo que determina o indivíduo, porque este depende de sua filiação, suportando o peso da 
tradição, o que explica que o grupo familiar se organize segundo uma ordem piramidal, em cujo ápice se encontra a figura do patriarca, potência tutelar e protetora (CHARAUDEAU, 2016, p. 36, tradução nossa ${ }^{4}$ ).

No caso dos discursos do impeachment, a alusão, na justificativa/legitimação do voto, à própria família do votante (sobretudo, mas também ao valor família em geral), foi mais expressivo entre os parlamentares de partidos considerados de direita ${ }^{5}$ apoiadores da destituição de Dilma Rousseff, o que reforça a tese acima de Charaudeau.

De fato, como disposto no Gráfico 1, partidos de esquerda e de centro-esquerda, como PT, PSOL, Rede, PCdoB e PDT foram os que menos expressaram o valor família. As exceções foram os partidos de direita PMB, que possuía, na época, somente uma cadeira, e o Partido Republicano (PR), que se diz combinar "os fundamentos do nacionalismo de Enéas Carneiro à doutrina do liberalismo social defendido por Álvaro Valle"

\section{Gráfico 1 - Menção à família por partido}

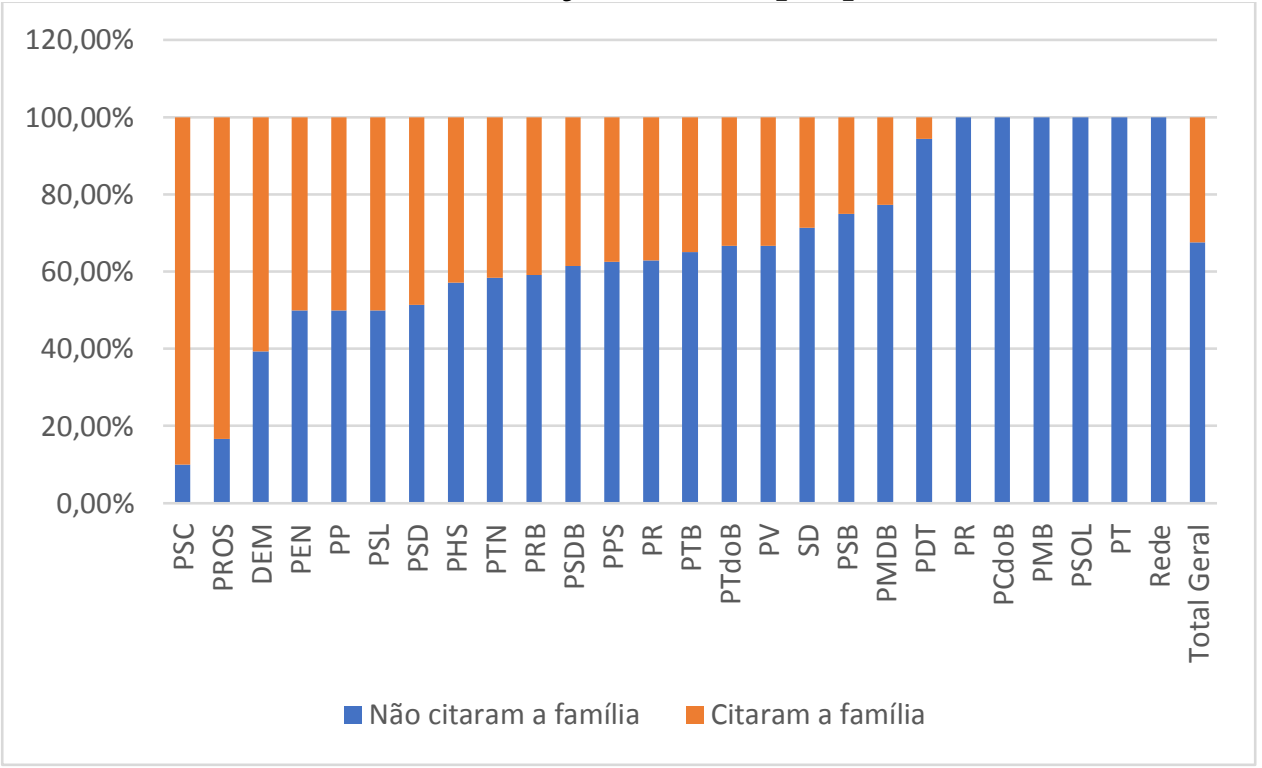

Fonte: elaboração do autor.

\footnotetext{
${ }^{4}$ La matrice idéologique de Droite se caractérise par une vision du monde dans laquelle "la nature s'impose à l'homme", ce qui veut dire que celui-ci lui est soumis, que donc l'inégalité est consubstantielle à la nature humaine, et que, par consequente, les rapports que les hommes entretiennent entre eux sont de rapports de force, voire de domination. Ce positionnement engendre la défense de certaines valeurs : la valeur du groupe famille puisque ce n'est pas l'individu qui fabrique le groupe mais le groupe qui détermine l'individu, cas celui-ci dépend de sa fililiation supportant ainsi le poids de la tradition, ce qui explique que le groupe famille s'organise selon un ordre pyramidal au sommet duquel se trouve la figure du patriarche, puissance tutélaire et protectrice.
}

${ }^{5}$ Para mais detalhes sobre estudos que versem sobre a classificação dos partidos brasileiros no espectro ideológico do discurso político, vide Chacon (1985), Madeira e Tarouco (2013), Mainwaring (1999), Oro e Mariano (2010), Quadros (2015), Rodrigues (1987, 2002) e Zucco Jr. (2009).

${ }^{6}$ Disponível em: < http://www.partidodarepublica.org.br/partido/historia_do_pr.html >. Acesso em: 05 de out. 2019. 


\section{Gráfico 2 - Menção à família por voto}

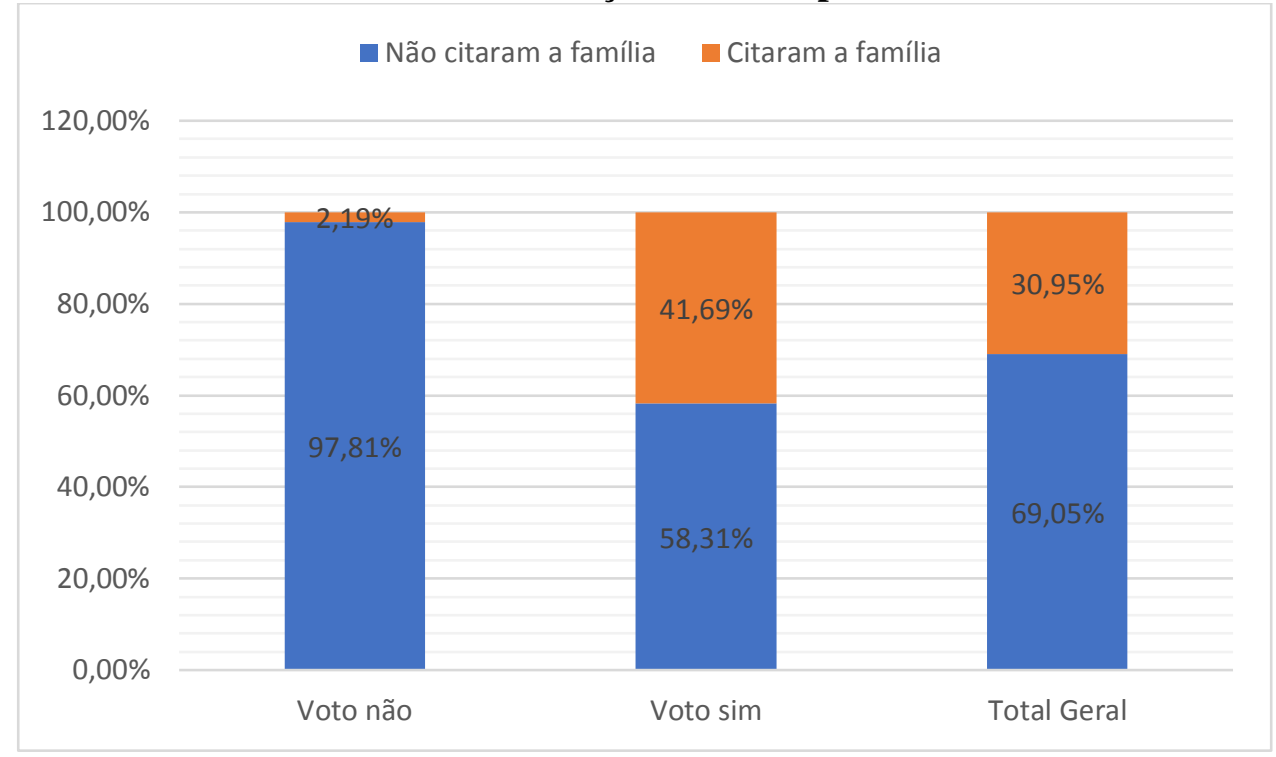

Fonte: elaboração do autor.

Pelo Gráfico 2, acima, percebe-se que existe uma considerável diferença entre os que votaram "sim" e "não ao impeachment no que diz respeito à menção à família, lembrando que, conforme o Gráfico 3, abaixo, existe uma relação entre um partido ser de esquerda e votar "não" ao impeachment. Enquanto 41,69\% dos que apoiaram o impeachment citaram a família, apenas 2,19\% dos que se opuseram à saída de Dilma Rousseff o fizeram.

Gráfico 3 - Votação por partido

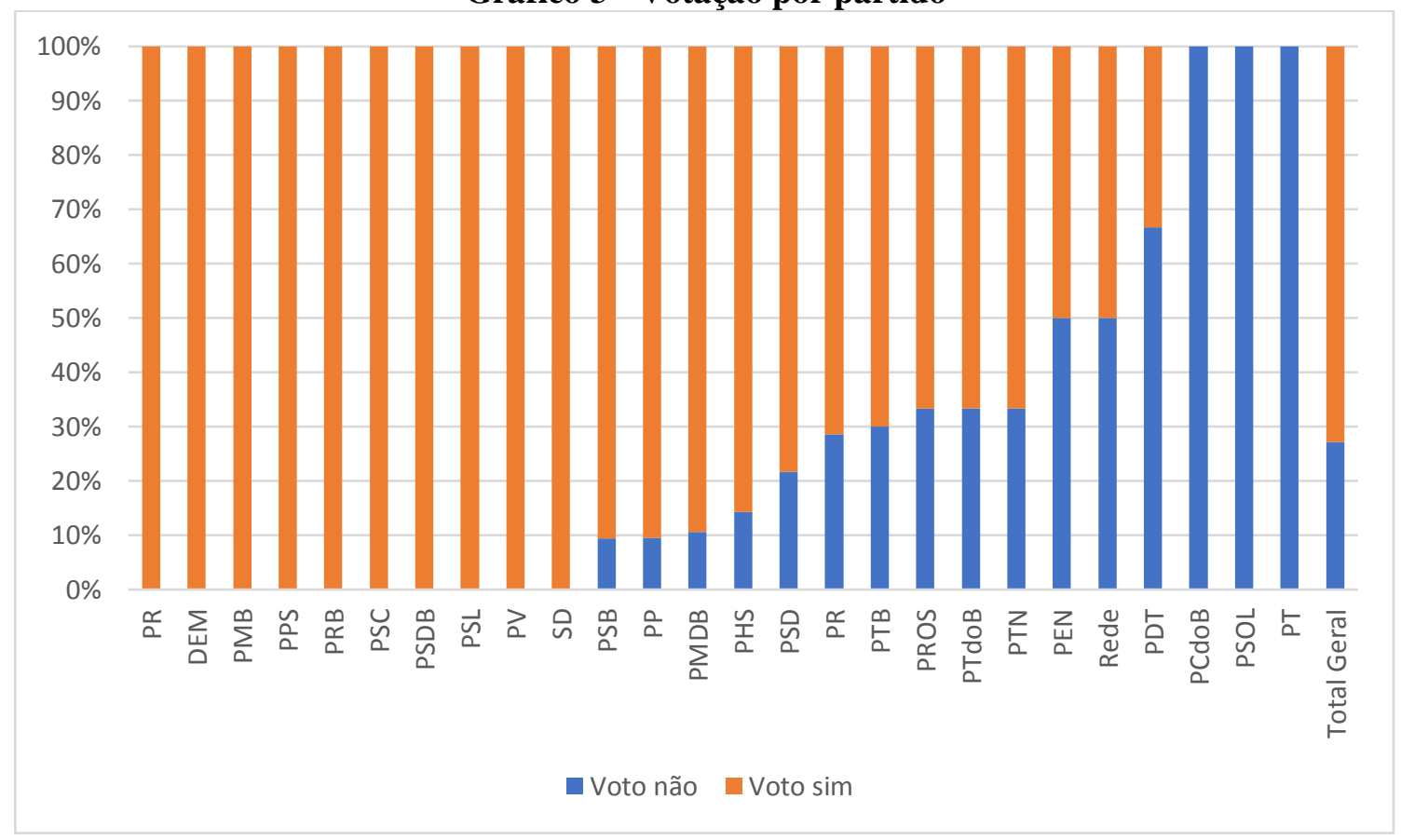

Fonte: elaboração do autor. 
Um aspecto que chama a atenção nesses pronunciamentos que, para deixarem a mensagem de que Dilma teria cometido crime de responsabilidade, citaram a família, é a mistura de questões concernentes ao domínio do privado na ordem pública. Quando o deputado Heráclito Fortes (PSB) substitui sua argumentação crítica em relação ao crime de responsabilidade para mandar um abraço à sua "mulher Mariana; às [suas] filhas Marianinha, Heloísa e Camila; aos [seus] netos Antônio e João; à [sua] neta que está por vir, Olímpia; à [sua] irmã Zélia; à [sua] tia Elzamir, com 96 anos" (ATA, 2016, p. 248), além de desprezar o que Grice (1989) chama de regra da pertinência, o deputado opera uma sutura entre o público e o privado. Teóricos do brasilianismo tenderiam, assim, a qualificar esse tipo de voto como, além de pertencente a uma matriz ideológica de direita, como o faz Charaudeau (2016), manifestações de uma cultura política patrimonialista.

Em Economia e Sociedade, Weber propõe que o patrimonialismo é o resultado da junção entre um modo de dominação tradicional, caracterizado pelo patriarcalismo, e uma dada ordem estamental (WEBER, 2000, 2004). Grosso modo, e desprezando aqui a evolução desse complexo conceito ao longo do pensamento weberiano, pode-se dizer que o estado patrimonialista é aquele cujos representantes se locupletam ou tomam a res pública como dimensão do privado:

A este caso especial da estrutura da dominação patriarcal: o poder doméstico descentralizado mediante a cessão de terras e eventualmente de utensílios a filhos ou outros dependentes da comunidade doméstica, queremos chamar de dominação patrimonial (WEBER, 2004, p. 238).

Continua Weber, em outro volume da mesma obra:

A dominação patrimonial e especialmente a patrimonial-estamental trata, no caso do tipo puro, igualmente todos os poderes de mando e direitos senhoriais econômicos e as oportunidades econômicas privadas apropriadas [...]. Para nossa terminologia, o decisivo é o fato de que os direitos senhoriais e as correspondentes oportunidades, de todas as espécies, são em princípio tratados da mesma maneira que as oportunidades privadas (WEBER, 2000, p. 155).

Segundo Raymundo Faoro, "a realidade histórica brasileira demonstrou [...] a persistência secular da estrutura patrimonial” (FAORO, 2001, p. 822). Desde o período da colonização portuguesa no Brasil,

[...] o golpe contra a burocracia, ao tempo que fere a corrupção, vibra a corda nacionalista, do embrionário nacionalismo do Brasil [...]. Em todos os botes a denúncia quer mostrar o domínio do funcionário, sombra do rei, infiel aos fins ideais do soberano, mas coerente com o patrimonialismo que este encarna e dirige [...]. O burocrata, já desenvolvido do embrião estamental do cortesão, furta e drena o suor do povo porque a seu cargo estão presos os interesses materiais da colônia e do reino. 
O súdito não é apenas o contribuinte, mas a vítima do empresário que arrenda os tributos, a vítima dos monopólios e das atividades da metrópole (FAORO, 2001, p. 203).

Para Faoro, o que se percebe no Brasil, portanto, é a perversão da lógica da cidadania que tem no povo a figura do soberano supremo, pressuposto de qualquer regime democrático. De “contribuinte-beneficiário", isto é, de contribuinte que paga seus impostos e que, por isso, será beneficiário de serviços públicos como contrapartida, o brasileiro, na verdade, mostrar-se-ia, na descrição de Faoro, como uma espécie de "contribuinte-vítima", por persistir em uma situação paradoxal em que, ao mesmo tempo em que investe no Estado pagando seus impostos para que este lhe garanta direitos básicos de subsistência e dignidade, é vítima daquele em que depositou sua confiança, espoliado que é pelos seus representantes políticos que veem no bem público uma dimensão de seu domínio privado.

Descrevendo o período logo após a independência do Brasil, Faoro conclui que, durante a época imperial:

A burguesia se enobrece com a compra de cargos, o pardo se afidalga com o uniforme das forças paramilitares. O cargo domestica turbulências dispersas, imantando, na sua dignidade, a submissão ao soberano. $\mathrm{O}$ velho $\mathrm{e}$ tenaz patrimonialismo português desabrocha numa ordem estamental, cada vez mais burocrática no seu estilo e na sua dependência. $\mathrm{O}$ rei, por seus delegados e governadores, domina as vontades, as rebeldes e as dissimuladas: "neste Estado há uma só vontade" - escrevia o padre Antônio Vieira, em 1655 - "e um só entendimento e um só poder, que é o de quem governa". O poder é o poder - esta a fórmula ainda dominante no Segundo Reinado, na palavra sem adjetivos de um tribuno, o primeiro que falou em nome de uma ficção, o povo" (FAORO, 2001, p. 242).

Vê-se que os cargos públicos no Brasil imperial eram objeto de compra e venda, tamanho o status que a posição conferia ao seu detentor. Quando Faoro menciona as "forças paramilitares", ele se refere aos capangas que circundam o funcionário, conferindo-lhe poderes de polícia para defender seu quinhão privado através da coisa pública. A conclusão é a de que quem possui o poder são os representantes políticos, e não o povo, essa ficção que naquele período servia para mascarar o caráter antidemocrático da civilização brasileira.

A miscigenação entre o público e o privado também é tratada por Faoro quando da descrição do coronelismo que, desde a era imperial, persiste na República Velha:

[...] o homem rico - o rico por excelência, na sociedade agrária, o fazendeiro, dono da terra - exerce poder político, num mecanismo onde o governo será o reflexo do patrimônio pessoal. [...] o coronel, economicamente autônomo, formará o primeiro 
degrau da estrutura política, projetada de baixo para cima [...]. [O coronel] recebe recebe ou conquista - uma fluida delegação, de origem central no Império, de fonte estadual na República, graças à qual sua autoridade ficará sobranceira ao vizinho, guloso de suas dragonas simbólicas, e das armas mais poderosas que o governador lhe confia. O vínculo que lhe outorga poderes públicos virá, essencialmente, do aliciamento e do preparo das eleições, notando-se que o coronel se avigora com o sistema da ampla eletividade dos cargos, por semântica e vazia que seja essa operação [...]. O patrimonialismo pulveriza-se, num localismo isolado, que o retraimento do estamento secular acentua, de modo a converter o agente público num cliente, dentro de uma extensa rede clientelista. O coronel utiliza seus poderes públicos para fins particulares, mistura, não raro, a organização estatal e seu erário com os bens próprios. Pisar no pé de um subdelegado ou do inspetor de quarteirão seria pisar no pé da lei, concretizado o incompreensível aparelhamento abstrato no terra-a-terra ridicularizado, se invertido o ângulo de visão" (FAORO, 2001, p. 737757).

Em Raízes do Brasil (1995), Sérgio Buarque de Holanda, por sua vez, considera o patrimonialismo como pedra angular na compreensão da categoria do que chama de "homem cordial" brasileiro. Eis o relato do autor:

No Brasil, onde imperou, desde tempos remotos, o tipo primitivo da família patriarcal, o desenvolvimento da urbanização - que não resulta unicamente do crescimento das cidades, mas também do crescimento dos meios de comunicação, atraindo vastas áreas rurais para a esfera de influência das cidades - ia acarretar um desequilíbrio social, cujos efeitos permanecem vivos ainda hoje (...). Não era fácil aos detentores das posições públicas de responsabilidade, formados por tal ambiente, compreenderem a distinção fundamental entre os domínios do privado e do público. Assim, eles se caracterizam justamente pelo que separa o funcionário "patrimonial" do burocrata conforme a definição de Max Weber. Para o funcionário "patrimonial", a própria gestão política apresenta-se como assunto de seu interesse particular; as funções, os empregos e os benefícios que deles aufere relacionam-se a direitos pessoais do funcionário e não a interesses objetivos, como sucede no verdadeiro Estado burocrático, em que prevalecem a especialização das funções e o esforço para se assegurarem garantias jurídicas aos cidadãos. A escolha dos homens que irão exercer funções públicas faz-se de acordo com a confiança pessoal que mereçam os candidatos, e muito menos de acordo com as suas capacidades próprias [...]. No Brasil, pode dizer-se que só excepcionalmente tivemos um sistema administrativo e um corpo de funcionários puramente dedicados a interesses objetivos e fundados nesses interesses. Ao contrário, é possível acompanhar, ao longo de nossa história, o predomínio constante das vontades particulares que encontram seu ambiente próprio em círculos fechados e pouco acessíveis a uma ordenação impessoal. Dentre esses círculos, foi sem dúvida o da família aquele que se exprimiu com mais força e desenvoltura em nossa sociedade. E um dos efeitos decisivos da supremacia incontestável, absorvente, do núcleo familiar - a esfera, por excelência, dos chamados "contatos primários", dos laços de sangue e de coração - está em que as relações que se criam na vida doméstica sempre forneceram o modelo obrigatório de qualquer composição social entre nós. (HOLANDA, 1995, p. 145-147).

Holanda ressalta a impregnação no fazer político da estrutura organizacional do modelo familiar baseado no pater familias, com suas hierarquias, seus ritos, suas leis baseadas na intimidade 
e respaldadas nos laços de sangue. Essa é uma realidade não muito distante da que hoje se observa no país, levando-se em consideração as constantes notícias sobre recebimento de propina por parte de governantes, a compra de votos para projetos que condizem a interesses particulares e não propriamente públicos, o fisiologismo, a política voltada para a permanência no poder, e não para a consecução do bem comum.

Percebendo esse discurso patrimonial entre alguns deputados na sessão do impeachment, há o exemplo de um voto que, trazendo a cena familiar para o espaço público, reflete o apreço da matriz ideológica de direita pela hierarquia, notadamente a cultura do mando do pater famílias, como o voto de Toninho Wandscheer (PROS-PR):

Em memória do meu pai, Paulo Wandscheer, que, tenho certeza, estaria mandando - ele nem pediria; ele mandaria - eu votar pela minha cidade, Fazenda Rio Grande, pelo meu Estado do Paraná, pela minha família e pelo meu Brasil querido, eu voto "sim" (ATA, 2016, p. 154).

Não só o valor da hierarquia é ressaltado no voto de Wandscheer, mas também o aspecto de autoritarismo a que Charaudeau faz referência, ao apontá-lo como uma tendência da matriz ideológica de direita, como explicado acima (CHARAUDEAU, 2016). A cultura do mando patriarcal estaria tão introjetada que faz com que o parlamentar tenha orgulho da mesma, ao ponto de usá-la para legitimar seu voto em relação ao crime de responsabilidade supostamente cometido por Dilma Rousseff.

Ao citar a própria família para justificar e/ou legitimar seu voto, o parlamentar não necessariamente toma uma atitude patrimonialista, mas sua fala pode ser reflexo de uma doxa que vê no espaço público a extensão de seus interesses particulares, ou então, em outros casos, de imposição de um modelo familiar tradicional a todos os integrantes da República. Trata-se de um valor que decorre daquela mesma lógica segregacionista de direita à qual se refere Charaudeau (2016), ao subtrair para a ordem do privado questões do domínio público, ou ao buscar excluir outras formas de manifestação familiar.

É o caso do voto de Ronaldo Fonseca (PROS-DF):

Venho a esta tribuna também, Sr. Presidente, representando a Frente Parlamentar Evangélica do Congresso Nacional, que tem lutado nesta Casa contra uma agenda de esquerda que quer destruir a família brasileira. Mas aqui nós temos Deputados aguerridos (ATA, 2016, p. 90).

Nesse sentido também é o voto de Éder Mauro (PSD-PA): 
[...] em nome do meu filho Éder Mauro Filho, de 4 anos, e do Rogério, que, junto com a minha esposa, formamos uma família no Brasil, que tanto esses bandidos querem destruir com propostas de que criança troque de sexo e aprenda sexo nas escolas, com 6 anos de idade, em nome de todo o povo do Estado do Pará, eu voto "sim" (ATA, 2016, p. 140).

E também o de Ronaldo Martins (PRB-CE):

Pelo povo de Deus, em defesa da família, tão atacada por este Governo, em nome do povo do meu Estado do Ceará, tão enganado por este Governo, pelo meu partido, pelo PRB, que segue unido, o meu voto é "sim" (ATA, 2016, p. 220).

Nota-se que os deputados demarcam bem o seu território na batalha cultural, ao adotarem um discurso conservador em defesa de um modelo familiar tradicional. Ronaldo Fonseca chega a se opor explicitamente contra uma "suposta agenda de esquerda que quer destruir a família brasileira".

Éder Mauro e Ronaldo Fonseca referem-se, concretamente, ao pejorativamente chamado “Kit Gay", um conjunto de materiais destinados à promoção da igualdade e da tolerância à diversidade sexual. O projeto Escola sem homofobia (seu nome original) foi vetado por Dilma Rousseff em 2011 quando estava para sair do papel, diante das pressões de sua base aliada conservadora no Congresso. O objetivo era o de promover "valores de respeito à paz e à não-discriminação por orientação sexual" (ESCOLA, 2004, apud MAZZOCO, 20157).

Concebido para ser distribuído entre professores, o material foi acusado pelos seus detratores como estimulante do "homossexualismo e da promiscuidade". No entanto, de acordo com Ricardo Desidério, autor de uma tese de doutorado sobre o referido Kit (SILVA, 2015), em entrevista ao site Nova Escola, o material visa a "desconstruir conceitos equivocados a respeito de identidade de gênero e orientação sexual [...] [esclarecendo] dúvidas do senso comum e [trazendo] referenciais da Ciência para introduzir a questão de gênero" (MAZZOCO, 2015). O conceito de gênero é tratado do ponto de vista biológico e sócio-histórico, de modo a explicitar como os papéis sociais associados ao masculino e ao feminino também estão presentes na escola, inclusive na forma como as disciplinas são transmitidas. Um exemplo são as aulas de Educação Física, em que os meninos geralmente são convocados a jogar futebol e as meninas, um outro esporte qualquer. Além do mais, segundo Desidério, modelos heteronormativos também estariam implícitos no conteúdo das matérias, o que contribuiria para a homofobia manifestada no Brasil pelos índices alarmantes de homicídios contra a população LGBT, fazendo com que o país, por exemplo, seja campeão mundial em matança de

\footnotetext{
${ }^{7} \mathrm{O}$ material pode ser acessado com exclusividade no site na ONG Nova Escola: https://novaescola.org.br/conteudo/1579/uma-analise-do-caderno-escola-sem-homofobia
} 
travestis e transexuais (BRASIL É O PAÍS, 2017). Um dado que por si só já justificaria a introdução de Educação Sexual nas escolas.

Ressalta Desidério, não é assente que "Educação Sexual nas escolas” seja uma ameaça nem mesmo ao modelo tradicional de família, pois, da análise da cartilha que iria ser divulgada nas escolas, não se infere a defesa de nenhum modelo familiar em específico. O que há é a promoção da tolerância para a possível coexistência pacífica entre diferentes formas de ser e de viver (SILVA, 2015).

A articulação da bancada evangélica, no entanto, foi incisiva. Os religiosos promoveram uma verdadeira guerra contra o Kit, estimulando seus fiéis a se mobilizarem em protestos, dentre os quais a "Marcha para Jesus" (KRAKOVICS, 2012).

No intuito de pressionar o veto de Dilma ao projeto "Escola sem Homofobia”, os deputados atrelados à causa ameaçaram paralisar o governo, não votando nada antes que o material educativo fosse recolhido. Sabendo-se que o então ministro da Casa Civil, Antônio Palocci, estava sendo investigado pela Polícia Federal, os parlamentares ligados às bancadas religiosas aproveitaram a situação para pressionar Dilma por meio de convocação do ministro para prestar esclarecimentos na Câmara dos Deputados, manobra política que depois foi admitida pelo então líder da bancada evangélica, João Campos de Araújo (CHAGAS, 2012).

De acordo com Fernando Haddad, então ministro da Educação, materiais que seriam destinados a caminhoneiros e profissionais do sexo foram apresentados à época pelo então deputado Jair Bolsonaro como sendo o material para as crianças. A cartilha das escolas, na verdade, teria sido o produto de um trabalho colaborativo com parlamentares progressistas e com ONGs, não tendo ainda sido aprovado pelo Ministério da Educação quando da polêmica (CHAGAS, 2012).

Outros votos que, também com menção à família, apoiaram o impeachment, deixando suas marcas referentes aos seus posicionamentos na guerra cultural foram o de Hiran Gonçalves (PP-RR) e o de Célio Silveira (PSDB-GO). O comum desses dois votos está no fato de ambos terem abordado o programa Mais Médicos, do governo federal, objeto de acirrados embates ideológicos. Eis o voto de Hiran Gonçalves:

Sr. Presidente, meu querido Brasil, pela minha família; pelos que me fizeram chegar até aqui; pelos médicos do Brasil, para que sejam respeitados pelo próximo governo; pelos maçons do Brasil e pelo bem do povo brasileiro, eu voto "sim", Sr. Presidente (ATA, 2016, p. 122).

Na mesma tônica, está o voto de Célio Silveira:

Sr. Presidente, pela minha querida Luziânia, pelo meu Entorno de Brasília, que tanto precisa de ação governamental, pelos médicos brasileiros, tão perseguidos por este 
desgoverno, pelo bravo e honrado povo de Goiás, por Daianne, Mateus e Adrianne, muda Brasil! "Sim” ao impeachment (ATA, 2016, p. 164).

Percebe-se que, na apreciação da plausibilidade ou não do cometimento de crime de responsabilidade por parte de Dilma Rousseff, ambos os deputados se furtaram à argumentação crítica e introduziram outros temas caros ao seu espectro ideológico no Brasil. Essa estratégia de mudar de tema é uma constante na Retórica da Guerra Cultural (SANTOS, 2019).

Entre outros elementos, como se vê, além de citarem a família, os parlamentares fizeram questão de defender os médicos do Brasil, supostamente desrespeitados pelo então governo. Trata-se de uma referência ao Mais Médicos, programa do governo lançado em 8 de julho de 2013 para suprir a carência de médicos no interior do país, onde tradicionalmente os profissionais não querem fixar residência.

O programa consistia na importação de médicos de Cuba, país conhecido pela sua excelência na área da saúde. Mas não só. Era um programa que objetivava a criação de mais vagas na graduação em cursos Medicina no Brasil e em residência médica. Entretanto, o aspecto da medida que ficou no imaginário de seus detratores foi a importação de mão-de-obra cubana, isto é, de um país "maculado" pela pecha do esquerdismo.

Para os dois deputados acima, servir uma população desassistida por profissionais da saúde, especialmente do nordeste do país, através do aumento da concorrência entre os médicos, seria uma forma de maltratá-los, justificativa suficiente, na visão dos parlamentares, para que Dilma Rousseff fosse destituída do cargo. Na verdade, não é propriamente exato que o governo fomentava a concorrência entre os médicos, uma vez que os profissionais cubanos eram alocados em regiões onde os profissionais brasileiros não queriam atuar (CAPETTI, 2019).

Pergunta-se, assim, se a reação de setores conservadores da sociedade seria a mesma se a suposta concorrência imposta aos médicos brasileiros decorresse de importação de médicos de outros países, dos EUA, por exemplo, ou de algum país desenvolvido e predominantemente branco da Europa.

A hipótese que fica é que o problema maior está no país escolhido para fornecer a mão-deobra. Vale lembrar que a palavra "Cuba" está impregnada no imaginário coletivo dos brasileiros e do latino-americano como locus por excelência da esquerda. Não é incomum, no Brasil, a imprecação, em tom de ofensa, de algum representante de direita dizendo o chavão "Vai pra Cuba!" para atacar alguém ou um discurso que considere esquerdista (VAI PRA CUBA, 2014).

Outro voto que, ao citar a família, mostrou seu campo de batalha na Retórica da Guerra Cultural foi o de Fausto Pinato (PP-SP): 
Sr. Presidente, Sras. e Srs. Deputados, em um momento este País escolheu a bandeira vermelha, mas viu que errou e quer novamente o verde-amarelo, a ordem e o progresso. Esse povo que está aí fora não veio da Venezuela, não veio da Coreia do Norte. Eu queria aqui, em nome da minha família, em nome da minha região noroeste do Estado de São Paulo, da minha cidade natal, votar "sim (ATA, 2016, p. 189).

Pinato coloca em um plano de oposição o vermelho, representado pelo atual governo de esquerda, e o verde-amarelo, o tradicional e saudoso lugar da "ordem e do progresso" que o brasileiro "quer novamente". Ao dizer que o povo que está nas ruas "não veio da Venezuela, não veio da Coreia do Norte", países associados à esquerda, o deputado sugere que o clamor popular é pelo retorno da velha ordem conservadora, o que, por si só, legitimaria o impeachment, ainda que, mais uma vez, a questão do crime de responsabilidade tenha passado ao largo das considerações do parlamentar.

Sobre a oposição vermelho versus verde-amarelo, ela se explica porque o vermelho adquiriu sua nuance de pertencer ao movimento das reivindicações populares durante a Revolução Francesa de 1789 (PASTOUREAU, 2014). Durante o período da Assembleia Constituinte, bandeiras vermelhas eram levantadas como uma forma de toque de recolher para que a população permanecesse em casa, indicando serem proibidas manifestações. Quando da destituição do rei Luís XVI, o prefeito de Paris içou bandeira vermelha, sem que a população acatasse a mensagem. Houve então um banho de sangue, e o vermelho, antes símbolo da opressão, passou a se associar às reivindicações populares. A partir daí, nas Revoluções na Europa de 1848, na bandeira da URSS e da China Comunista, o vermelho começou a ser associado a tudo que se opunha à velha ordem autoritária e antipopular, mesmo que na maioria dos regimes de bandeira vermelha o autoritarismo tenha sido a pedra de toque.

Quanto ao verde-amarelo, no Brasil, as cores são tradicionalmente ligadas à elite nacionalista e conservadora, desde o movimento literário verde-amarelo da década de 1930, até as manifestações pró-impeachment de Dilma Rousseff em 2016 (ROCHA, 2016). O movimento verde-amarelismo (como também é chamado) tinha como um de seus expoentes Plínio Salgado, o mesmo que ajudou a fundar o integralismo, uma doutrina de contornos xenofóbicos e de inspiração fascista (TRINDADE, 2004).

Soraya Santos (PMDB-RJ) procede ao mesmo jogo de referências:

[...] por andar por este Brasil afora e ver milhões de brasileiros nas ruas vestindo verde-amarelo, de forma pacífica, ordeira, mostrando que os seus filhos não fogem à luta — não precisam invadir casa de ninguém [...]; por minha família, e neste momento eu me faço representar pelos meus netos, Arthur, Sofia e a mais nova, a caçula, que está chegando; eu quero dizer aos brasileiros, à minha cidade de Niterói e ao meu Estado do Rio de Janeiro que voto "sim". Impeachment já! (ATA, 2016, p. 241). 
A parlamentar delimita, nesse voto, seu lado na Retórica da Guerra Cultural ao tratar de forma positiva "os milhões de brasileiros nas ruas vestindo verde-amarelo, por oposição aos vermelhos, apresentados de forma negativa, na figura do Movimento dos Trabalhadores Rurais Sem Terra (MST, associado às esquerdas), quando fala em invasão de casas. Os verde-amarelos "não fogem à luta" (uma referência ao Hino Nacional), manifestando de forma "pacífica, ordeira", civilizada, ao contrário dos vermelhos, bárbaros invasores de terra.

Curioso notar que a deputada ressalta que se faz representar não pelo povo (que não é monolítico, mas diverso e apresenta fraturas), mas por seus "netos, Arthur, Sofia e a mais nova, a caçula, que está chegando". Assim, Soraya Santos deixa transparecer em sua fala, ainda que não seja sua real intenção (o que não vem ao caso aqui) uma cultura patrimonialista de confusão entre o espaço público e o privado.

Talvez o voto que tenha manifestado o mais alto grau dessa cultura patrimonialista tenha sido o de Eduardo da Fonte (PP-PE):

Sr. Presidente, Sras. e Srs. Deputados, ao lado do meu filho Luiz Eduardo, que aqui está, em nome da minha família, eu gostaria de, primeiro, pedir a Deus que abençoe o Brasil. Eu vou passar a palavra ao meu filho, para que ele possa dizer ao Brasil o meu voto (ATA, 2016, p. 305).

Eduardo da Fonte não se limitou a citar sua família, mas quis ainda que seu filho Luiz Eduardo votasse em seu lugar. Simbolicamente, tem-se aí uma manifestação da intrusão do privado sobre o público, uma vez que o parlamentar legou a seu descendente a prerrogativa de representante do povo, o verdadeiro titular do poder político em regimes democráticos, tal como dispõe a cláusula pétrea da Constituição do Brasil em seu art. 1, parágrafo único: “todo o poder emana do povo, que o exerce por meio de representantes eleitos ou diretamente [...]".

Vê-se, portanto, que o deputado toma como natural o fato de seu familiar se arrogar o direito de apreciar o crime de responsabilidade de Dilma Rousseff, substituindo a argumentação crítica própria dos espaços públicos democráticos de sociedades abertas (DANBLON, 2004) pela delegação de poder hereditária.

Como se percebe do tratamento das manifestações dóxicas e dos valores até aqui, os votos a favor do impeachment foram os que mais apresentaram contornos de uma matriz ideológica de direita. A menção a Deus, o nacionalismo/regionalismo e a citação da família, incorporados a outros temas polêmicos da guerra cultural no Brasil, denunciaram as tendências ao conservadorismo, ao segregacionismo e, às vezes, ao autoritarismo, características gerais da matriz ideológica de direita, para Bobbio (2011) e Charaudeau (2016). 


\section{CONSIDERAÇões FINAIS}

Uma das conclusões a que se chega, quanto à votação do impeachment de Dilma Rousseff na Câmara dos Deputados, é que os proferimentos foram atravessados por uma polêmica pública de fundo que concerne aos embates culturais presentes na sociedade brasileira. Dilma Rousseff, quando popular e quando o país não sofria os impactos de uma crise econômica, fazia parte de uma coligação bastante heterogênea, incluindo setores conservadores da sociedade, pertencentes às bancadas da bala, ruralista e religiosas, por exemplo.

No entanto, tendo sua popularidade caído, os impactos da crise econômica se fazendo observar, e as manifestações conservadoras da população aumentando, através do acesso direto ao espaço público pelas redes sociais e das grandes marchas pró-impeachment, muitos deputados desembarcaram do governo, dando fim ao chamado "consenso de esquerda". Assim, os deputados favoráveis à saída da presidente foram, em sua maioria, aqueles que apresentaram marcas de um discurso da matriz ideológica da direita conservadora, de acordo com os critérios de Bobbio (2011) e Charaudeau (2016).

Efetivamente, entre os que votaram a favor do impeachment, percebeu-se o recurso predominantemente a elementos dóxicos e a valores da direita conservadora, como a introdução de uma cena patrimonialista nos pronunciamentos, seguida, por atração isotópica, de outros lugares afeitos a esse campo ideológico, com a menção aos valores da família tradicional, da ordem, e da religião. Do ponto de vista dos partidos, foram exatamente aqueles classificados como de direita, por meio de estudos em Ciência Política (como os de Oro e Mariano (2010) e de Rodrigues (2002), por exemplo), que encamparam a tese do impeachment.

Espera-se que o trabalho possa lançar luzes não só em relação aos estudos sobre o discurso político, notadamente no que diz respeito ao problema do patrimonialismo, mas que também possa subsidiar pesquisadores de diferentes áreas que se debruçam sobre a temática do impeachment de Dilma Rousseff.

\section{REFERÊNCIAS}

AMOSSY, Ruth. A Argumentação no discurso. São Paulo: Contexto, 2018.

ATA da $91^{\text {a }}$ Sessão da Câmara dos Deputados, Deliberativa Extraordinária, Vespertina, da $2^{\text {a }}$ Sessão Legislativa Ordinária, da 55ª Legislatura, em 17 de abril de 2016. Sessão: 091.2.55.0. Departamento de taquigrafia, revisão e redação. Câmara dos Deputados. Brasil.

BOBBIO, Norberto. Direita e Esquerda: razões e significados de uma distinção política. São Paulo: Editora Unesp, 2011. 
BRASIL É O PAÍS que mais mata travestis e transexuais. Estado de Minas, 2017. Disponível em: http://www.em.com.br/app/noticia/especiais/dandara/2017/03/09/noticia-especialdandara,852965/brasil-e-pais-que-mais-mata-travestis-e-transexuais.shtml. Acesso em 06 de set. 2017.

CAPETTI, Pedro; COUTO, Marien. Mais Médicos: após saída de cubanos, $42 \%$ das cidades têm vagas abertas. $O$ Globo. 25 de maio 2019. Disponível em : https://oglobo.globo.com/brasil/maismedicos-apos-saida-de-cubanos-42-das-cidades-tem-vagas-abertas-23694511. Acesso em: 15 nov. 2019.

CHACON, Vamireh. História dos Partidos Brasileiros: Discurso e práxis dos seus programas. Brasília: Editora da Universidade de Brasília, 1985.

CHAGAS, Angela. Deputado. Opção sexual é assunto da vida privada, não da escola. Terra. 23 de mai. 2012. Disponível em: http://noticias.terra.com.br/educacao/deputado-opcao-sexual-e-assuntoda-vida-privada-nao-da-escola,2d6a42ba7d2da310VgnCLD200000bbcceb0aRCRD.html. Acesso em: 15 nov. 2019.

CHARAUDEAU, Patrick. Du discours politique au discours populiste. Le populisme est-il de droite ou de gauche? In: CORCUERA, F. et al. (org.). Les discours politiques. Regards croisés. Paris: L'Harmattan, 2016, p.32-43.

CHARAUDEAU, Patrick. Les stéréotypes, c'est bien. Les imaginaires, c'est mieux. In: BOYER, H. (dir.). Stéréotypage, stéréotypes: fonctionnements ordinaires et mises en scène. Paris: L'Harmattan, 2007.

DANBLON, Emmanuelle. Argumenter en démocratie. Bruxelles: Éditions Labor, 2004.

FAORO, Raymundo. Os Donos do Poder: a formação do patronato político brasileiro. Rio de Janeiro: Globo, 2001.

GRACIO, Rui. Para uma teoria geral da argumentação: questões teóricas e aplicações didáticas. 2010. 446f. Tese (Doutorado) - Universidade do Minho. Instituto de Ciências Sociais. Braga, 2010.

GRICE, Paul. Logique et conversation. Comunications, n. 30, 1979.

HOLANDA, Sérgio Buarque de. Raízes do Brasil. São Paulo: Companhia das Letras, 1995.

KRACOVICS, Fernanda. Outra vez, aborto e união gay na pauta eleitoral. O Globo. 21 de jul. 2012. Disponível em: https://oglobo.globo.com/brasil/eleicoes-2012/outra-vez-aborto-uniao-gay-napauta-eleitoral-5549617. Acesso em: 17 nov. 2019.

MADEIRA, Rafael Machado; TAROUCO, Gabriela da Silva. Partidos, programas e o debate sobre esquerda e direita no Brasil. Revista de Sociologia e Política. Curitiba, v. 21, n. 45, 2013, p. 149165.

MAINWARING, Scott. Rethinking party systems in the third wave of democratization: The Case of Brazil. Stanford: Stanford University Press, 1999.

MAZZOCO, Bruno. Uma análise do caderno Escola sem Homofobia. Nova Escola, 01 de fev. 2015. Disponível em: https://novaescola.org.br/conteudo/1579/uma-analise-do-caderno-escola-semhomofobia. Acesso em: 06 set. 2017.

ORO, Ari; MARIANO, Ricardo. Eleições 2010: religião e política no Rio Grande do Sul. Debates do NER. Porto Alegre, ano 10, n. 16, 2010, p. 9-34.

PASTOUREAU, Michel; SIMONNET, Dominique. Le petit livre des couleurs. Paris: Seuil, 2014.

PLANTIN, Christian. Dictionary of argumentation: an introduction to argumentation studies.

Milton Keynes: Lightning source, 2018. 
QUADROS, Marcos Paulo dos Reis. O conservadorismo à brasileira: sociedade e elites políticas na contemporaneidade. 2015. 273f. Tese (Doutorado) - Pontifícia Universidade Católica do Rio Grande do Sul, Programa de Pós-Graduação em Ciências Sociais. Porto Alegre, 2015.

RODRIGUES, Leôncio Martins. Partidos, ideologia e composição social. Revista Brasileira de Ciências Sociais, n. 48, v. 17, 2002, p. 31-47.

RODRIGUES, Leôncio Martins. Quem é quem na Constituinte: uma análise sócio-política dos partidos e deputados. São Paulo: Oesp-Maltese, 1987.

SANTOS, Frederico Rios C. dos. A Retórica da Guerra Cultural no Parlamento brasileiro: a argumentação no impeachment de Dilma Rousseff. 2019. 315f. Tese (Doutorado) - Universidade Federal de Minas Gerais, Programa de Pós-Graduação em Linguística. Belo Horizonte, 2019.

SILVA, Ricardo Desidério. Educação Audiovisual da Sexualidade: olhares a partir do Kit AntiHomofobia. 2015, 144 f. Tese (Doutorado em Educação Escolar). Faculdade de Ciências e Letras, Universidade Estadual Paulista, Araraquara-SP, 2015.

TRINDADE, Hélgio. O nazi-fascismo na América Latina. Porto Alegre: UFRGS Editora, 2004.

"VAI PRA CUBA!" é um grito que escorre como bílis dos lábios dos neorreacionários. DCM. 28 de nov. 2014. Disponível em: https://www.diariodocentrodomundo.com.br/vai-pra-cuba-e-um-gritoque-escorre-como-bilis-dos-labios-do-neo-reacionarios/. Acesso em: 21 jul. 2018.

WEBER, Max. Economia e Sociedade: fundamentos da sociologia compreensiva. Brasília: Editora Universidade de Brasília, 2000. v. 1

WEBER, Max. Economia e Sociedade: fundamentos da sociologia compreensiva. Brasília: Editora Universidade de Brasília, 2004. v. 2.

ZUCCO JR., Cesar. Ideology or what? Legislative behavior in multiparty presidentialist settings. Journal of Politics, Arizona, v. 71, n. 3, 2009, p. 1076-1092. 